Piotr CICHOSZ ${ }^{1}$

Paweł KAROLCZAK ${ }^{2}$

Maciej KOWALSKI ${ }^{3}$

Marek KOLODZIEJ ${ }^{4}$

Hubert SKOWRONEK ${ }^{5}$

Kamil WASZCZUK ${ }^{6}$

\title{
FAZOWNIK SAMOCZYNNY Z OSTRZEM NAPINANYM SPRĘŻYNĄ ŚRUBOWĄ
}

\begin{abstract}
Współczesna technologia dąży do maksymalnej efektywności wytwarzania z zachowaniem odpowiedniej dokładności wytwarzanych elementów. Załamywanie krawędzi realizowane standardowymi metodami może być czasochłonne. Fazowanie narzędziami samoczynnymi, dostępnymi na rynku, nie gwarantuje odpowiedniej dokładności wymiarów i właściwości fazek, szczególnie w produkcji seryjnej. $\mathrm{W}$ pracy przedstawiono ideę fazowania narzędziem posiadającym ostrze z płozą ślizgową, napinane sprężyną śrubową. Pokazano proces konstrukcji tego narzędzia. Zaprezentowano jego końcową wersję oraz wybrane wyniki fazowania tym narzędziem. Pokazano główne zalety takiego fazownika wraz z jego wadami, a także zasugerowano możliwe dalsze usprawnienia konstrukcji narzędzia, które mogą wady te wyeliminować.
\end{abstract}

Słowa kluczowe: narzędzie skrawające, płoza ślizgowa, krawędź, fazowanie

\section{Wprowadzenie}

W większości elementów konstrukcyjnych części maszyn występują krawędzie, które wymagają załamania. Wykonanie fazy jest niezbędne z kilku powodów. Najważniejszymi są [2]: uniknięcie wykruszenia krawędzi, ułatwienie i usprawnienie montażu, usunięcie gratu i zadziorów. Fazowanie będące prostym zabiegiem bardzo często jest wykonywane w operacjach kształtujących procesu technologicznego. Niestety, mimo swojej prostoty załamywanie krawędzi może stwarzać wiele problemów, szczególnie w przypadku krawędzi trudno dostępnych. W takich przypadkach czasochłonność i kosztochłonność fazowania jest

\footnotetext{
2 Autor do korespondencji/corresponding author: Paweł Karolczak, Politechnika Wrocławska, ul. Łukasiewicza 5, 50-371 Wrocław, tel.: 713202075, e-mail: pawel.karolczak@pwr.edu.pl.

1,3,4,5,6 Piotr Cichosz, Marek Kołodziej, Maciej Kowalski, Hubert Skowronek, Kamil Waszczuk; PolitechnikaWrocławska, e-mail: piotr.cichosz@pwr.edu.pl; marek.kolodziej@pwr.edu.pl; maciej.kowalski@pwr.edu.pl; hubert.skowronek@pwr.edu.pl; kamil.waszczuk@pwr.edu.pl
} 
zazwyczaj bardzo duża, co może silnie rzutować na efektywność wytwarzania. Spotykane są procesy technologiczne, gdzie samo załamywanie krawędzi jest głównym składnikiem czasu wytwarzania gotowego wyrobu, co staje się szczególnie wyraźne i kłopotliwe w produkcji masowej. Dodatkowym czynnikiem, ważnym w procesie fazowania jest dokładność wykonania fazek. Problem ten jest często pomijany i marginalizowany. Jednak w sytuacji, gdy wymagane jest wykonanie dokładnych i powtarzalnych fazek, okazuje się, że jest to bardzo trudne, a w wielu przypadkach wręcz niewykonalne.

Znanych jest wiele metod usuwania zadziorów i fazowania krawędzi [2]. Na rynku są też dostępne liczne narzędzia przeznaczone specjalnie do fazowania i usuwania zadziorów. Pozwalają one na samoczynne wykonanie fazek, zazwyczaj na krawędziach otworów. Ich działanie polega głównie na tym, że elastycznie zamocowane ostrze odchyla się pod wpływem siły odporowej skrawania i załamuje krawędź. Narzędzia te mają jednak liczne wady, które sprawiają, że niemożliwe jest ich zastosowanie do dokładnego fazowania w produkcji seryjnej i masowej, z powodu dużej losowości procesu. Wytwarzane tymi narzędziami fazki nie są powtarzalne, a ich wymiary, dokładność oraz chropowatość są uzależnione od takich czynników, jak: zmienne właściwości i stan warstwy wierzchniej materiału półfabrykatu oraz wielkość i nieregularność zadziorów. Efektem wystąpienia tych wad jest brak możliwości zastosowania jednego typu narzędzi do różnych materiałów obrabianych i konieczność przeprowadzania testów przed przystąpieniem do dokładnego fazowania. Dlatego też poszukuje się takich rozwiązań i konstrukcji narzędzi, które pozwoliłyby na dokładne wykonywanie fazek bez względu na istniejące opory skrawania, przy jednoczesnym znacznym skróceniu czasu jednostkowego obróbki.

Losowość wykonania fazki i zakłócenia procesu fazowania mogą być zminimalizowane przy zastosowaniu konstrukcji narzędzia zgodnego z patentem [1]. W konstrukcji tej ostrze jest umieszczone w gnieździe korpusu narzędzia i dociskane sprężyście do powierzchni oporowych. Część robocza ostrza jest wyposażona w krawędzie skrawające oraz płozy ślizgowe. Krawędź skrawająca obrabia do chwili, gdy płoza ślizgowa zetknie się z materiałem obrabianym w miejscu, gdzie powinna się kończyć faza. Wówczas skrawanie zostaje przerwane, bowiem płoza ślizgowa cofa ostrze w kierunku promieniowym. Proste mechanizmy pozwalają na ustawienie wykonania żądanych wymiarów fazki na wlocie i wylocie otworu. Umiejscowienie tego mechanizmu bezpośrednio lub pośrednio za pomocą kasetki w korpusie innego narzędzia umożliwia wykonanie otworu, wraz ze sfazowaniami, w jednym przejściu narzędzia.

\section{Konstrukcja narzędzia}

Pierwsza konstrukcja narzędzia do fazowania krawędzi z ostrzem sprężystym została zaprezentowana w pracy [3]. Badania funkcjonalności tej konstrukcji pokazały, że możliwe jest dokładne wykonanie fazek narzędziami, których 
ostrze posiada płozę ślizgową. Potwierdzono dużą uniwersalność tego rozwiązania do fazowania na powierzchniach osiowosymetrycznych zewnętrznych i wewnętrznych. Możliwe stało się też kształtowanie fazek o bardziej kontrolowanych wymiarach niż za pomocą innych narzędzi z grupy o elastycznie mocowanych ostrzach, szczególnie gdy fazki kształtowano w materiałach plastycznych.

Obiecujące pierwsze próby oraz coraz większe zapotrzebowanie przemysłu na samoczynne narzędzia do fazowania skłoniły do dalszych prac nad udoskonalaniem konstrukcji tego typu narzędzi. Badania te prowadzono we współpracy z Pabianicką Fabryką Narzędzi PAFANA S.A. Najważniejszymi wymaganiami stawianymi narzędziom były: możliwość kształtowania fazek na obu krańcach otworu, o zdefiniowanych wymiarach niezależnie od właściwości obrabianego materiału, rozłożenia naddatku i wielkości zadziorów. Dodatkowo, projektowane narzędzia powinny zapewniać regulację wielkości kształtowanej fazy, a także możliwość łączenia ich z innymi narzędziami, tworząc narzędzia wielozadaniowe. Efektem prowadzonych prac były 3 podstawowe konstrukcje narzędzi do samoczynnego fazowania krawędzi. Jedną z nich jest fazownik z ostrzem napinanym elementem sprężystym śrubowym.

Proces konstruowania narzędzia do wykonywania fazek podzielono na dwa prowadzone równolegle etapy. Dotyczyły one konstrukcji ostrza wraz z płozą ślizgową oraz postaci elementu sprężystego. Pierwszym pomysłem, wydawałoby się najprostszym, było wykorzystanie na ostrza fazownika płytek skrawających handlowych. Zaletą takiego rozwiązania jest niewątpliwie unifikacja ostrza, co mogłoby obniżyć całkowite koszty produkcji narzędzi. Wadą jest na pewno konieczność wykonania dokładnego gniazda, w którym przesuwa się płytka, o przekroju prostokątnym lub trapezowym. Niestety, nie jest to rozwiązanie technologiczne. Wada ta jest zminimalizowana w przypadku narzędzia z kasetką, ponieważ ostrze zostało przymocowane do przesuwającej się kasetki. Nie ma potrzeby (w tej wersji narzędzia) wykonania dokładnie pasowanego gniazda kwadratowego czy trapezowego. Przygotowano kilka koncepcji takiego rozwiązania, w tym: konstrukcję kasetki narzędzia z ostrzem z częścią prowadzącą o przekroju prostokątnym oraz z ostrzem o walcowej części prowadzącej (rys. 1).

W związku z nietechnologicznością rozwiązania z płytką o przekroju kwadratowym ustalono, że korzystniejsze będzie wykonanie ostrza wraz ze zintegrowaną płozą ślizgową $\mathrm{z}$ okrągłego pręta węglikowego, oferowanego handlowo w klasie dokładności wykonania powierzchni walcowej g6.

W zaproponowanych konstrukcjach wysunięcie ostrza (B) z korpusu narzędzia, będące regulacją wielkości tworzonej fazki jest realizowane przez śrubę regulacyjną (A). W związku z koniecznością zachowania dużej dokładności wykonania narzędzi i stabilności położenia kątowego ostrza podczas pracy postanowiono zabezpieczyć konstrukcję przed wykręcaniem się śrub regulacyjnych za pomocą specjalnych wkładek gwintowych, w których jeden zwój jest wykonany w kształcie wielokąta. 


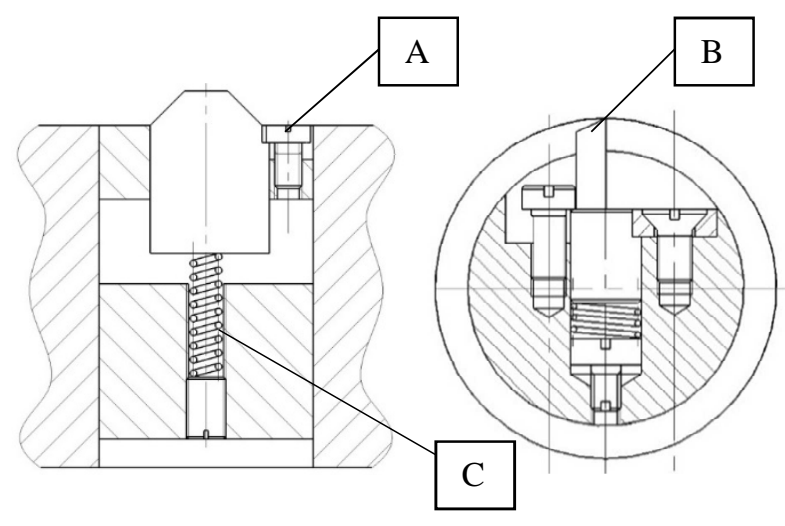

Rys. 1. Koncepcja fazownika z płytką skrawającą o przekroju prostokątnym (z lewej) i okrągłym (z prawej); A - śruba regulująca, B - ostrze, C - sprężyna śrubowa napinająca ostrze

Fig. 1. Concept of the chamfering tool with square (left) and circular (right) insert in cross-section; A - adjusting screw, $\mathrm{B}$ - blade, $\mathrm{C}$ - helical spring tensioning the blade

Drugim istotnym zagadnieniem był odpowiedni dobór elementu sprężystego napinającego ostrze. Wysokie wymagania, jakie są stawiane tym elementom, sprawiają, że w takich narzędziach możliwe było zastosowanie elementów sprężystych, śrubowych, piórowych lub talerzowych. Dokładną analizę tych elementów przedstawiono w artykule [4]. Sprężyny śrubowe są bardzo często stosowane w różnych mechanizmach, dlatego były jednym z pierwszych wyborów w konstrukcji fazowników. Ich najważniejszymi zaletami jest równomierne wytężenie materiału wzdłuż całej długości sprężyny przy jednoczesnym minimalizowaniu lub braku jej odkształcenia plastycznego. Dodatkową zaletą jest niewątpliwie liniowa charakterystyka podatności sprężyn śrubowych. Pomimo to dość trudnym zagadnieniem był prawidłowy dobór charakterystyki sprężyny, tak aby dawała możliwość docisku ostrza z siłą większą niż odporowa siła skrawania, przy jednoczesnej odpowiednio dużej możliwości przesuwu ostrza. Ponadto, wadą elementów napinających śrubowych w kontekście ich zastosowań w fazownikach jest to, że siła, jaką mogą one wywierać, działa wzdłuż ich długości. Utrudnia to, a nawet ogranicza możliwość jej prostopadłego usytuowania w stosunku do osi w narzędziach o małych średnicach [4]. Dlatego też narzędzia do fazowania $\mathrm{z}$ ostrzami napinanymi sprężynami śrubowymi w ograniczonym zakresie mogą podlegać miniaturyzacji. Po analizie i wstępnych próbach dobrano sprężyny naciskowe o oznaczeniu G 10-025, charakteryzujące się zwiększoną sztywnością. Na rysunku 2 pokazano prototyp narzędzia z ostrzem napinanym elementem śrubowym. Narzędzie to zostało oznaczone jako fazownik 4.0. 
Rys. 2. Narzędzie do fazowania z ostrzem napinanym sprężyną śrubową

Fig. 2. A tool for chamfering with a blade tensioned by the helical spring

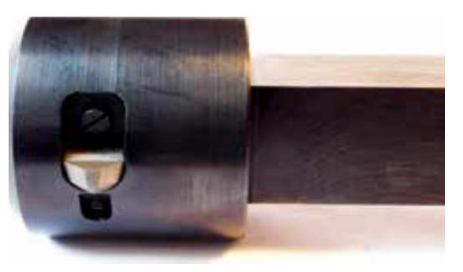

\section{Badania doświadczalne wykonywania fazek}

Badania funkcjonalności fazownika $\mathrm{z}$ ostrzem napinanym elementem sprężystym śrubowym przeprowadzono dla dwóch materiałów obrabianych, czyli dla stali C55 i żeliwa EN GJL 250. W pierwszym etapie oceniono, jak duże powinno być napięcie elementu sprężystego, aby przewyższało opory skrawania, jakie są konieczne do wykonywania fazek o założonych maksymalnych wymiarach. Próby eksperymentalne pokazały, że siła napięcia sprężyny powinna się zawierać w zakresie 50-150 N, w zależności od zakładanej wielkości fazki. Na rysunkach 3 i 4 pokazano przykładowe sfazowania krawędzi w tulei żeliwnej, otrzymane w warunkach obróbki na sucho (rys. 3) i ze smarowaniem (rys. 4). Z kolei na rys. 5 i 6 przedstawiono fazki wykonane w tulei stalowej. Obróbkę przeprowadzono z napięciem elementu sprężystego 50; 100 oraz $150 \mathrm{~N}$, co odpowiadało zakładanym w badaniach różnym wielkościom wykonywanych fazek: brak fazki (usunięcie gratu); $0,7 \times 45^{\circ} ; 1,8 \times 45^{\circ}$. Badania przeprowadzono dla parametrów skrawania, które są stosowane w obróbce wykończeniowej (posuw $f=0,08$ $\mathrm{mm} /$ obr., prędkość skrawania $v_{c}=45 \mathrm{~m} / \mathrm{min}$ ). Niewielka zastosowana prędkość skrawania wynikała z faktu, że przy większych jej wartościach występowały niestabilne warunki pracy, objawiające się niewielkimi zaburzeniami szerokości fazki. Otrzymane fazy rejestrowano i fotografowano za pomocą urządzenia DinoLite. Dodatkowo zmierzono siły skrawania siłomierzem tokarskim firmy Kistler.
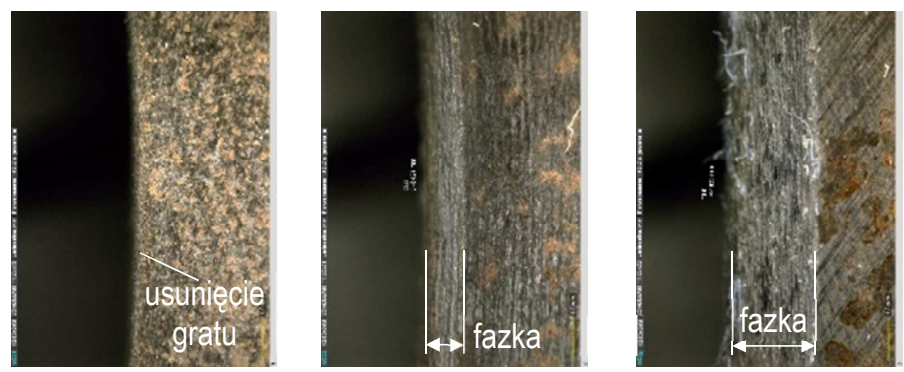

Rys. 3. Fazy wykonane w żeliwie w warunkach obróbki na sucho; wymiary fazek od lewej - brak fazki (usunięcie gratu), $0,6 \times 45^{\circ}, 1,45 \times 45^{\circ}$

Fig. 3. Chamfers made in cast iron under machining with dry conditions; chamfer dimension from left - no chamfer (removal of burr), $0.6 \times 45^{\circ}$, $1.45 \times 45^{\circ}$ 

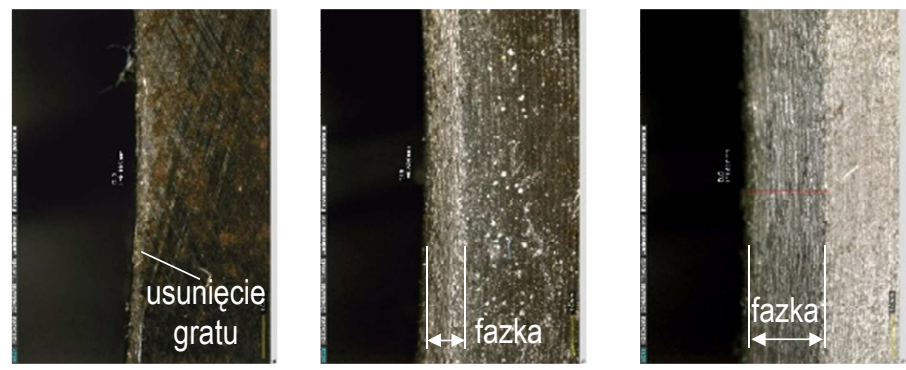

Rys. 4. Fazy wykonane w żeliwie w warunkach obróbki ze smarowaniem; wymiary fazek od lewej - brak fazki (usunięcie gratu), $0,6 \times 45^{\circ}, 1,35 \times 45^{\circ}$

Fig. 4. Chamfers made in cast iron under machining with lubrication; chamfer dimension from left - no chamfer (removal of burr), $0.6 \times 45^{\circ}$, $1.35 \times 45^{\circ}$
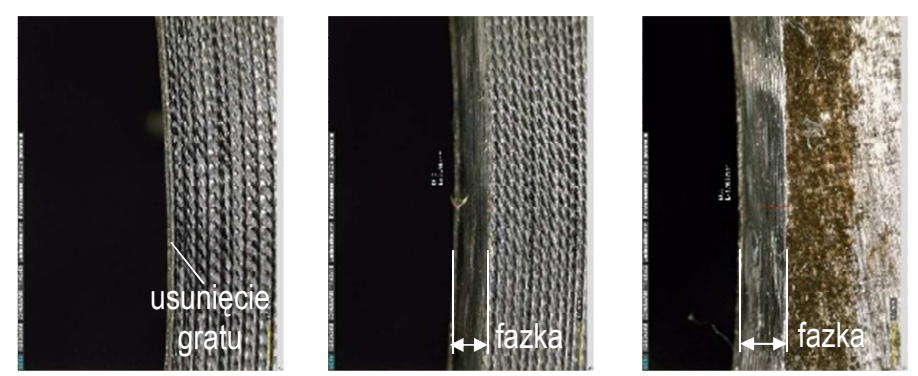

Rys. 5. Fazy wykonane w stali w warunkach obróbki na sucho; wymiary fazek od lewej - brak fazki (usunięcie gratu), $0,55 \times 45^{\circ}, 0,8 \times 45^{\circ}$

Fig. 5. Chamfers made in steel under machining with dry conditions; chamfer dimension from left - no chamfer (removal of burr), $0.55 \times 45^{\circ}$, $0.8 \times 45^{\circ}$
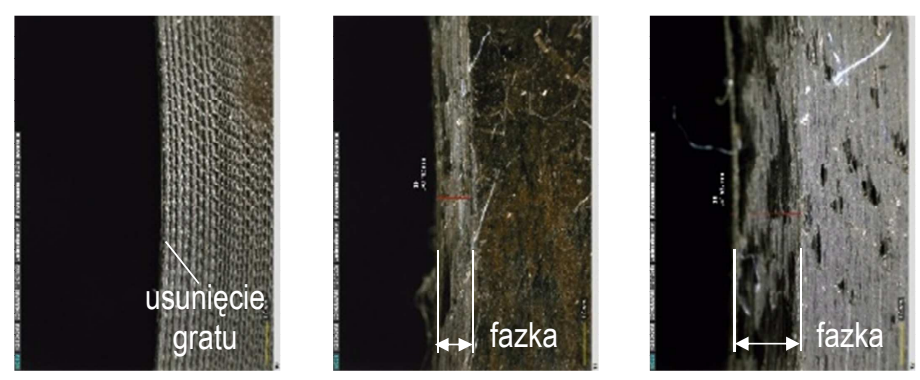

Rys. 6. Fazy wykonane w stali w warunkach obróbki ze smarowaniem; wymiary fazek od lewej - brak fazki (usunięcie gratu), $0,55 \mathrm{x} 45^{\circ}, 1,1 \mathrm{x} 45^{\circ}$

Fig. 6. Chamfers made in steel under machining with lubrication; chamfer dimension from left - no chamfer (removal of burr), $0.55 \times 45^{\circ}, 1.1 \times 45^{\circ}$ 
Analizując otrzymane wyniki, stwierdzono, że skonstruowane narzędzie umożliwia wykonywanie fazek. Otrzymano fazy zarówno w tulei stalowej, jak i żeliwnej, w szerokim zakresie wymiarów. Ich jakość, szczególnie pod względem kształtu, była zadowalająca. Istotny był fakt, że w przypadku zastosowania takich samych nastaw fazownika otrzymano fazy powtarzalne, o podobnych parametrach jakościowych. Z drugiej strony, takie czynniki wejściowe do procesu, jak materiał obrabiany, parametry skrawania zmieniały wielkość i jakość otrzymanej fazy, co sprawiało, że przy każdej zmianie warunków procesu należało zmienić nastawy narzędzia. Brak smarowania lub jego zastosowanie w przypadku większego napięcia sprężyny i większej oczekiwanej fazy miały wpływ na wielkość powstającej fazy - przy zastosowaniu smarowania uzyskano większe fazy w stali, a mniejsze w żeliwie. Nie zmieniała się natomiast znacząco jakość fazek. Należy zatem stwierdzić, że wadą narzędzia jest brak możliwości czytelnego oznaczenia nastaw fazownika, które utrudnia dokładne zaplanowanie wielkości otrzymanej fazy. Powoduje to wydłużenie czasu ustawienia narzędzia dla konkretnych warunków obróbki i wymagań co do wielkości fazy, co z kolei może ograniczyć zastosowanie tego narzędzia jedynie do produkcji seryjnej.

\section{Podsumowanie}

Załamywanie i gratowanie krawędzi to ważny, choć często marginalizowany problem w technologii. Gdy w elemencie obrabianym fazki muszą mieć określone wymiary i właściwości, a dodatkowo jest ich dużo i są w trudno dostępnych miejscach, problem z ich kształtowaniem staje się większy. Prowadzone są prace nad skonstruowaniem narzędzi, najlepiej wielozadaniowych, ułatwiających fazowanie. Przedstawiony w pracy fazownik z płozą ślizgową i ostrzem napinanym sprężyną śrubową daje możliwość wykonania dokładnej i powtarzalnej fazki bez względu na materiał obrabiany i warunki obróbki. Wersja narzędzia przedstawiona w artykule pozwala na regulację wielkości powstającej fazki. Niestety, regulacja ta jest czasochłonna i uciążliwa. Różnica pomiędzy wielkością otrzymanej fazy a jej wymiarami oczekiwanymi zwiększała się wraz ze zwiększaniem się wymiarów fazy. Kolejne prace powinny być nastawione na ułatwienie regulacji lub przygotowanie dokładnych wytycznych ustawienia nastaw fazownika dla bardzo szerokich zestawów wielkości wejściowych do procesu.

\section{Literatura}

[1] Cichosz P.: Ostrze do samoczynnego wykonywania fazek, Patent PL 213332, zgłoszono 14.09.2009, udzielono patentu 28.02.2013.

[2] Cichosz P., Kuzinovski M.: Metody wykonywania fazek i gratowania krawędzi, Mechanik, 84 (2011) 553-559.

[3] Cichosz P., Kuzinovski M., Szymański W.: Możliwości kształtowania fazek i gratowania krawędzi narzędziami z ostrzami sprężystymi, [w:] Obróbka skrawaniem współczesne problemy, red. B. Kruszyński, Łódź 2010. 
[4] Cichosz P., Karolczak P., Kołodziej M., Kowalski M., Kuzinovski M., Skowronek H., Waszczuk K.: Elementy sprężyste fazowników samoczynnych, Mechanik, 89 (2016) 1424-1427.

\section{THE SELF-ACTING CHAMFERING TOOL WITH BLADE TENSIONED BY HELICAL SPRING}

\section{S u m m a r y}

Modern technology strives to maximum productivity while maintaining the correct accuracy of manufactured components. Chamfering of the edges by standard methods increases the production time. Chamfering with self-acting tools available on the market does not guarantee the proper dimensions and properties of the chamfer, especially in mass production. This paper presents the idea of chamfering by the tool with a sliding blade and tensioned with helical spring. The construction processes of this tool have been shown. Its final version and selected chamfering results are presented. The main advantages of such a chamfer with its disadvantages are shown, and further possible improvements to the design of the tool, which can eliminate disadvantages, are suggested.

Keywords: cutting tool, sliding skid, edge, chamfering

DOI: $10.7862 / \mathrm{rm} .2017 .44$

Przestano do redakcji: 24.08 .2017

Przyjęto do druku: 18.10 .2017

Projekt finansowany przez Narodowe Centrum Badań i Rozwoju w ramach programu: INNOTECH III 